\title{
Temperatures and precipitation totals over the Russian Far East and Eastern Siberia: long-term variability and its links to teleconnection indices
}

\author{
V. V. Krokhin ${ }^{1}$ and W. M. J. Luxemburg ${ }^{2}$ \\ ${ }^{1}$ Laboratory of Natural System Modeling, Pacific Institute of Geography, FEB RAS, Russia \\ ${ }^{2}$ Delft University of Technology, Faculty of Civil Engineering, Section of Water Resources, The Netherlands \\ Received: 22 March 2006 - Published in Hydrol. Earth Syst. Sci. Discuss.: 26 July 2006 \\ Revised: 30 October 2007 - Accepted: 16 November 2007 - Published: 27 November 2007
}

\begin{abstract}
The present study examines the spatial-temporal regime of the mean monthly temperature (MMT) and monthly precipitation (MPT) anomalies over the Russian Far East and Eastern Siberia for the period 1949-2003. The original data were analyzed spatially by means of complex principal component analysis and temporally by means of the maximum entropy method and traditional Fourier spectral analysis. The interannual variability in these anomalies can be represented by the single dominant modes. These dominant modes oscillate with periods of about $2-3 \mathrm{yr}$ and $6-8 \mathrm{yr}$ that are accompanied by statistically significant changes in such monthly teleconnection indices, as the Arctic and North Pacific Oscillations.
\end{abstract}

\section{Introduction}

The variations of surface-air temperature and precipitation are of vital social and economic importance (Watson et al., 2001). However, there is uncertainty in the question how climatic systems evolve. One of the ways to solve this problem is a study of the interconnections between above-listed parameters and numerous teleconnection indices, which were revealed by many researchers in different times (Bell and Halpert, 1995). From studies (Barnston and Livizey, 1987; King et al., 1998; Thompson and Wallace, 2000) we know that the different teleconnection indices can reflect the major part of multi-scale variability of the atmospheric dynamics. After that, many investigators showed that variations in the teleconnection indices involve surface air temperature and precipitation (Thompson et al., 2000; Cavazos, 2000; Rodriguez-Puebla et al., 2001).

Correspondence to: V. V. Krokhin

(krokhin@mail.ru)
There has been great interest in the Arctic Oscillation (AO), which was introduced as an annular mode by Thompson and Wallace $(1998,2000)$. Another well known climate decennial-scale phenomenon, named the North-Pacific Oscillation when it was first discovered, has recently been represented by the Pacific decadal oscillation or PDO (Biondi et al., 2001; Mantua et al., 1997). Many works have indicated that AO and NP Oscillations significantly influence regional temperate climates in the Northern Hemisphere (for example: Gershunov and Barnett, 1998; Gong et al., 2003; Overland et al., 1999; Thompson et al., 2000).

However, the many details of the timescale and long-term dynamics of the AO and NP Oscillations are not well understood. Especially this is true for the regional temperate monsoon climates, and for the region of the East Asian monsoon in particular. Based on the long term temperature and precipitation observed in the Russian Far East and Eastern Siberia, here we present evidence that there are significant connections between AO/NP indices and the mean monthly temperature (MMT) and the monthly precipitation (MPT) anomalies for the East Asian monsoon region on the interannual time scale for the years 1949-2003. Also, in this work the complex analysis of the spatial-temporal regime of the mean monthly temperature (MMT) and monthly precipitation (MPT) anomalies is carried out for the Russian Eastern Siberia and the Russian Far East for the period 1949-2003.

In Sect. 2, we describe the precipitation and temperature data, AO index and NP index (also referred to as the PDO index). The methods are presented in Sect. 3. The results of the complex analysis of the spatial-temporal regime of MMT\&MPT anomalies and its interrelation to AO/NP indices are presented in Sects. 4 and 5, respectively. A discussion follows in Sect. 6. A conclusion follows in Sect. 7.

Published by Copernicus Publications on behalf of the European Geosciences Union. 
Station Distribution

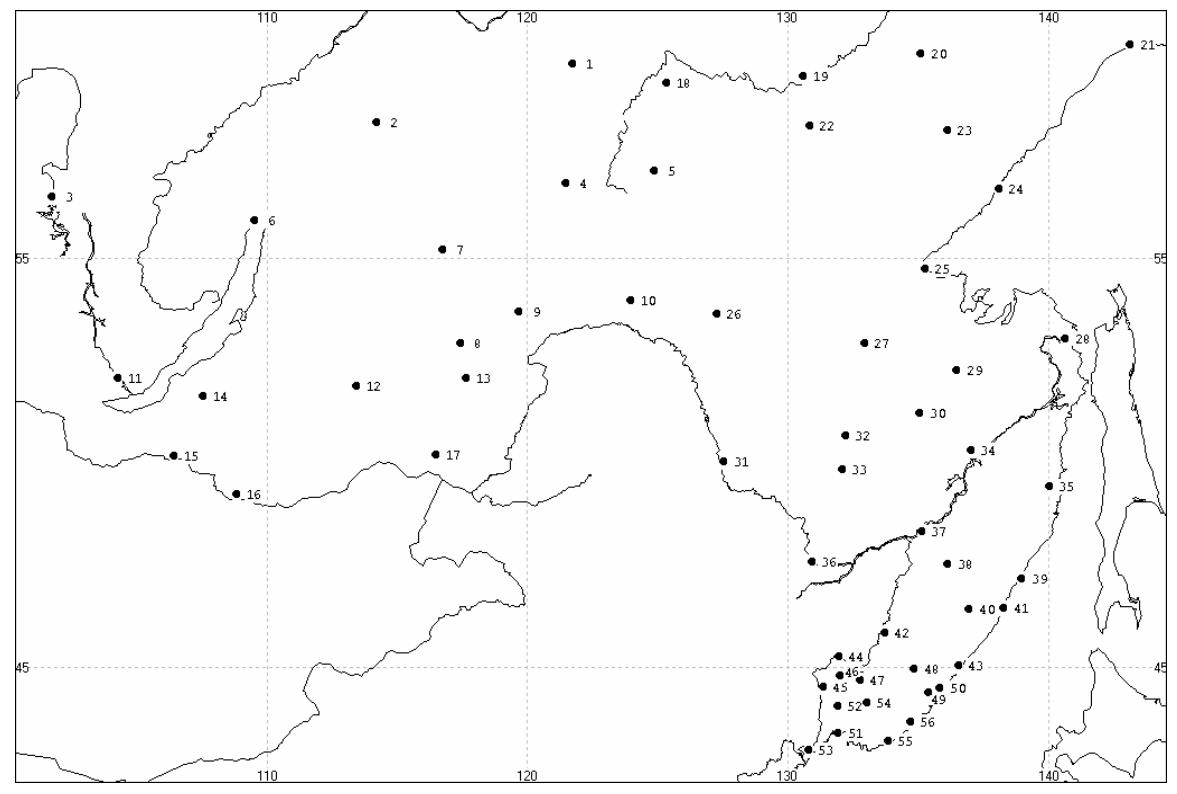

Station Names

$\begin{array}{llll}\text { 1. Djikimda } & \text { 15. Kjahta } & \begin{array}{l}\text { 29. Im. Poliny } \\ \text { Osipenko }\end{array} & \text { 43. Ternej } \\ \text { 2. Bodajbo } & \text { 16. Menza } & \text { 30. Hularin } & \text { 44. Turij Rog } \\ \text { 3. Bratsk } & \text { 17. Borzja } & \text { 31. Blagoveshhensk } & \text { 45. Pogranichnyj } \\ \text { 4. Ust-Nukja } & \text { 18. Aldan } & \text { 32. Chekunda } & \text { 46. Astrahanka } \\ \text { 5. Chulman } & \text { 19. Uchur } & \text { 33. Sutur } & \text { 47. Spassk-Dal'nij } \\ \text { 6. Nizhne-Angarsk } & \text { 20. Ust-Yudoma } & \begin{array}{l}\text { 34. Komsomol'sk-na- } \\ \text { Amure }\end{array} & \text { 48. Roshhino } \\ \text { 7. Kalakan } & \text { 21. Ohotsk } & \text { 35. Tumnin } & \text { 49. Bogopol' } \\ \text { 8. Zilovo } & \text { 22. Chulbu } & \text { 36. Ekaterino- } & \text { 50. Rudnaja Pristan' } \\ & & \text { Nikol'skoe } & \\ \text { 9. Mogocha } & \text { 23. Nelkan } & \text { 37. Habarovsk } & \text { 51. Vladivostok } \\ \text { 10. Skovorodino } & \text { 24. Ayan } & \text { 38. Gvasugi } & \text { 52. Timirjazevskij } \\ \text { 11. Irkutsk } & \text { 25. Chumikan } & \text { 39. Zolotoy Cape } & \text { 53. Pos'et } \\ \text { 12. Chita } & \text { 26. Zeya } & \text { 40. Ohotnichij } & \text { 54. Anuchino } \\ \text { 13. Sretensk } & \text { 27. Ekimchan } & \text { 41. Sosunovo } & \text { 55. Preobrazhenie } \\ \text { 14. Ulan-Ude } & \text { 28. Nikolaevsk-na- } & \text { 42. Dal'nerechensk } & \text { 56. Margaritovo } \\ & \text { Amure } & & \end{array}$

Fig. 1. The locations of 56 stations where temperature and precipitation was measured over Eastern Siberia and the Far East from 1949 to 2003.

\section{Data}

$\mathrm{AO}$ indices are determined by time series of the leading principal component of the monthly mean $1000 \mathrm{gPa}$ height in the Northern hemisphere (poleward of $20^{\circ} \mathrm{N}$ ). We used the monthly AO index series dataset with time coverage of 1949 to 2003. The AO index dataset is available from internet at http://www.cdc.noaa.gov/ClimateIndices/List/.

$\mathrm{NP}$ indices are determined by time series of the leading mode of sea surface temperature variability (poleward of $20^{\circ} \mathrm{N}$ ). We used the monthly NP index series dataset with time coverage of 1949 to 2003. The NP index dataset is available from internet at http://www.cdc.noaa.gov/ ClimateIndices/List/.
At present the gridded precipitation and temperature data are available from National Centers for Environmental Prediction, the National Center for Atmospheric Research (NCEP-NCAR) and the web-site (http://www.cru.uea.ac.uk/ $\sim$ mikeh/) from the University of East Anglia (Hulme and Jones, 1993). However, it is well known that the interpolation of data, especially precipitation, from individual station locations to a regular grid proved to be critical (White, 2000), and, therefore, we used the stations data only.

Time series of monthly precipitation and monthly mean temperatures are determined by 56 stations around Eastern Siberia and the Far East (Fig. 1) approximately between $41^{\circ} \mathrm{N}-60^{\circ} \mathrm{N}$ and $100^{\circ} \mathrm{E}-144^{\circ} \mathrm{E}$. Each 55 -year series begins in 1949 and ends in 2003. Data series were provided by the 
Far East Regional Hydrometeorological Research Institute (Russia). Accurate long-term climate analysis requires homogeneous data, therefore, inhomogeneities in temperature and precipitation were detected and inhomogeneous series were adjusted by researchers in FERHRI (Svinukhof et al., 1977; Gonzalez-Rouco et al., 2001).

\section{Methods}

Our method is based on the combination of "low-pass filtering + complex principal component analysis + spectral analysis" (Ghil and Yiou, 1996; Yuan and Martinson, 2000).

The complex principal component analysis (CPCA), maximum entropy method (MEM) and traditional Fourier crossspectral analysis techniques have been used to study traveling phenomena in the anomaly time series and their connectivity with different teleconnection indices. For carrying out the CPCA we used the author's package based on IMSL programs (International Mathematical and Statistical Library, 1982).

Multivariate analysis methods, especially the complex empirical orthogonal function method, assume the data to be complete. When there are gaps the resulting complex correlation matrix shall be ill conditioned, it will be even not a positive definite and the numeric procedure will give several small negative eigenvalues. A way of overcoming this problem is to fill the missing data using an adequate method. In the study we recovered missing data with the help of simulation techniques based on Bayesian inference for multivariate data with missing values. The computational routine NORM is described by Schafer (1997). NORM (version 2.02) is a Windows 95/98/NT program for multiple imputations of incomplete multivariate data. The program is available on personal Schafer's site (http://www.stat.psu.edu/ jls/). Note, however, that the portion of the missing data did not exceed $3 \%$, and, therefore, distortion of the climatic signal is low.

As a first stage, the precipitation and temperature anomaly time series were conditioned for the analysis. The precipitation and temperature anomaly time series are affected by strong spatial-temporal (spectra-like) noise and local quasi "errata" values. Fortunately, the temporal variability of anomaly time series was found spatially coherent at scales larger than the spatial noise (Genthon et al., 2003).

It is well known that monthly precipitation time series do not have a Gaussian function distribution, so a square root transformation was applied to the data (Krokhin, 2000).

The precipitation and temperature anomaly time series, i.e. after removing the seasonal cycle, contained inter-annual and longer variability as well as linear trends. Then we removed any linear trend at every station point. Note, that the procedure is a requirement needed both for low-pass filtering and a Hilbert transform (see the text below).

A main limitation of the performance of the complex empirical orthogonal function analysis is that the modal spatial patterns from a time domain analysis of wide-banded signals should be interpreted cautiously (Merrifield and Guza, 1990). Therefore, the precipitation and temperature anomaly time series were filtered by a Butterworth's low-pass symmetric filter (Rabiner and Gold, 1975) to eliminate noise with periods less than 1 year prior to the variability analysis. Next, in order to minimize Gibbs's end effects during spectral analysis the first and last $10 \%$ time steps of the time series were tapered using a portion of a cosine bell distribution (Bloomfield, 2000).

At second stage, we used the complex time series analysis, which allows decomposing space-time signals (of the precipitation and temperature anomaly time series) into different modes when the variance is spread over a number of frequencies. The complex principal component analysis is a method which allows introduction of a temporal dimension in the classical principal component analysis for studying traveling waves in the atmosphere. Barnett (1983), Horel (1984) and Davis et al. (1991) present a detailed description, which is summarized here. The complex principal component analysis method consists of transforming the original spatial-temporal data set $u(j, t)$ into a complex signal $U(j, t)$ with coincident and quadrature information, i.e.

$U(j, t)=u(j, t)+i v(j, t)$,

where $j$ is a spatial position index, $j=1,2, \ldots, J$, and $t$ is the time index, $t=1,2, \ldots T$. The imaginary part of (1) is called the Hilbert transform. In the study it was obtained with the Hilbert transform of the original real time series using the Herrmann's time-domain filtering technique (1969). The complex representation in (1) can be expressed as the sum of the empirical orthogonal modes (CEOF), in case $J<T$ i.e.

$U(j, t)=\sum_{n=1}^{J} A_{n}(t) B_{n}^{*}(j)$

where the asterisk denotes complex conjugation. The timedependent principal components are given by

$A_{n}(t)=\sum_{j=1}^{J} U(j, t) B_{n}(j)$

where $B_{n}(j)$ is the complex eigenvector of the $n$-th mode. In practical terms, to obtain the real eigenvalues and the complex eigenfunctions, we should solve the eigenvalues problem of the Hermitian covariance matrix C. Its elements $C(j, k)$ are the complex covariances between the $j$-th and the $k$-th spatial position. This implies that

$C(j, k)=\left\langle U^{*}(j, t) U(k, t)\right\rangle_{t}$

where the asterisk denotes complex conjugation, $\langle\ldots\rangle_{t}$ indicates a time averaging process, $U(j, t)$ and $U(k, t)$ are the complex signals from Eq. (1) at location $j$ and $k$, for time $t=1,2, \ldots T$, and $j$ and $k$ are the spatial position indexes, $j$, $k=1, . ., J$. 
The result of the CEOF analysis is represented by four functions, i.e. the spatial amplitude $S_{n}(x)$, temporal amplitude $R_{n}(t)$, spatial phase $\Theta_{n}(x)$ and temporal phase function $\phi_{n}(t)$

$S_{n}(x)=\left[B_{n}(x) B_{n}^{*}(x)\right]^{1 / 2}$

$R_{n}(t)=\left[A_{n}(t) A_{n}^{*}(t)\right]^{1 / 2}$

$\Theta_{n}(x)=\arctan \left[\frac{\operatorname{Im} B_{n}(x)}{\operatorname{Re} B_{n}(x)}\right]$

$\phi_{n}(t)=\arctan \left[\frac{\operatorname{Im} A_{n}(t)}{\operatorname{Re} A_{n}(t)}\right]$,

where $x$ denotes the location $x(j), j=1,2, \ldots J$.

The spatial amplitude $S_{n}(x)$ describes the spatial distribution of variability and can be interpreted as in a normal EOF analysis. The temporal amplitude $R_{n}(t)$ shows temporal variability in magnitude. The spatial phase $\Theta_{n}(x)$ shows the relative phase of fluctuations among the different spatial locations. The temporal phase function $\phi_{n}(t)$ describes the temporal variation of phase.

So, the variance can be decomposed into different modes, as for a classical component analysis, but the modes are no longer associated with only static variability, but with a dynamic one, taking into account the time evolution on the variability. Furthermore, the spatial patterns of only two dominant complex principal components were complex rotated orthogonally by the Varimax method (Kaiser, 1958; Bloomfield and Davis, 1994). The choice to rotate only two first complex modes is based on further analysis of the variance of the first five complex modes. The orthogonal rotation solution is ".... less dependent on the domain of the analysis" (Horel, 1984:1665).

At third stage, the traditional Fourier cross-spectral analysis has been used to find interrelations between the leading time-dependent complex principal components (see Eq. 3) of the precipitation and temperature anomaly time series and the teleconnection indices (NP and AO). Cross-spectral analysis of coherence was obtained by a Fast Fourier Transform using the Welch's periodogram technique (Welch, 1967; Jenkins and Watts, 1968; Brillinger, 1981).

At final stage, the maximum entropy method has been used to estimate the power spectra of the leading time-dependent complex principal components (see Eq. 3) of the precipitation and temperature anomaly time series and the teleconnection indices (NP and AO). Note that although a CPCA is a very powerful method for identifying waves or modes, an advantage of spectral analysis is that the techniques for determining the statistical significance of the results are better developed. Maximum entropy spectral analysis is a technique that can be used for relatively short and noisy time series when one needs more spectral resolution than provided by the classic Fourier spectral analysis (Press et al., 1992).
The maximum entropy method will tend to strongly localize spectral peaks. In practice, we used it in conjunction with the traditional Fourier spectral analysis (Bloomfield, 2000).

In order to establish the significance of periodic signal components in the analyzed time series in the presence of white noise, Siegel's test was used. Siegel's test is the most powerful test against many periodicities, i.e., for cases in which up to three periodic components are present in a time series (Percival and Walden, 1993). Schultz and Stattegger (1997) present a detailed description, which we show only in summary here. Siegel's test is based on large values of the normalized periodogram with statistics

$T=\sum_{k=1}^{K}\left(\frac{P\left(f_{k}\right)}{\sum_{j=1}^{K} P\left(f_{j}\right)}-\lambda g_{0}\right)$

where $K$ is the number of Fourier frequencies and $g_{0}$ is the Fisher's critical value, that can be computed by $g_{0} \approx 1-\left(\frac{\alpha}{K-1}\right)^{\frac{1}{K-1}} . \lambda$ is an empirical parameter that has to be specified by the researcher. Results on studies by Schultz and Stattegger (1997) suggest that our choice of $\lambda=0.4$ works in many practical situations. For $20<K<2000$ critical values of $T_{\lambda, \alpha}$ can be approximated by

$T_{\lambda, \alpha} \approx a K^{b}$,

where the empirical coefficients $a$ and $b$ equal 0.9842 and -0.51697 , respectively, for a significance level $\alpha=0.05$.

\section{Complex principal component analysis on precipita- tion and temperature anomaly time series}

In an attempt to identify coherent spatial/temporal substructure in the anomaly time series, a CPCA was applied to identify traveling and standing waves (Horel, 1984).

Earlier, Salinger (1980a, b), Domroes et al. (1998), Varlamov et al. (1998), Rodrigues-Puebla et al. (2001) established that time series of temperature and precipitation anomalies in the different geographical regions could be represented with relatively few empirical orthogonal function modes. Later, White and Cherry (1999) found out that interannual variability in temperature and precipitation time series in New Zealand can be represented by a single dominant mode.

Here, we also demonstrate that interannual variability in Eastern Siberian and Far Eastern time series of temperature and precipitation anomalies can be represented by the first dominant modes. Only complexity of the spatial modes increase beyond several propagating features of irregular form, the easy interpretations are generally no longer possible, although some useful information can still be derived from the analysis (cf. Barnett, 1983). Note however, that all first dominant modes are statistically significant, according to 
Preisendorfer's rule-N (Preisendorfer, 1988). Determination of all statistically significant modes was not considered.

The CPCA of temperature anomalies yields the first mode explaining 55\% of the total interannual variance (for comparison: the second, third, fourth and fifth modes explain $13 \%, 6 \%, 4 \%$, and $3 \%$, respectively). The complex empirical orthogonal functions are presented here in terms of its amplitude (arrow length) (Fig. 2a) and phase (arrow direction) (Fig. 2b). The vector pointing upwards (downwards) indicates that real and imaginary eigenvector components are in-phase (out-of-phase), a vector pointing to the right (left) indicates that the real part lags the imaginary part on $1 / 4$ of a period. For example, the clockwise vector rotation from west to east indicates that the wave travels eastward (Horel, 1984; Tourre et al., 1999). In our case, the phase angle over our pattern remains quasi-constant, indicating that the temperature anomalies evolution is stationary. So, the temperature variability over our domain can be represented by a standing wave component.

However, "...precipitation variability is relatively elusive ... " (Genthon et al., 2003; citation from Interannual Antarctic tropospheric circulation and precipitation variability, 2003). Mode discrimination and sorting through CPCA is thus more difficult and unreliable for precipitation than for temperature. Therefore we analyzed the first mode only. The remaining part of the total interannual variance is too inconsistent and noisy to be further analyzed with confidence. The dominant mode of the precipitation anomalies pattern (Fig. 3a and b) represents only $22 \%$ of the total low-pass interannual variance (for comparison: the second, third, fourth and fifth modes explain $10 \%, 8 \%, 6 \%$ and $4 \%$, respectively). The relative parity among the weights in the real and imaginary components of the precipitation dominant mode (not shown) indicates that precipitation anomalies have a greater propagational character associated with them than do temperature anomalies. In other words, this mode is a superposition of progressive and standing waves. Some eastward and equator directed spreading of the climatic signal occurs over our domain. This is shown by a clockwise rotation of vectors over Eastern Siberia and the Far East. The eastward and equator directed propagation is consistent with the direction of propagation in atmospheric anomalies associated with the Arctic Oscillation. This is true for the middle latitudes in both the Southern and Northern Hemispheres (White and Cherry, 1999; White, 2000; Ambaum et al., 2001).

The real components of the temperature and precipitation anomaly time series for dominant complex principal modes lag the imaginary components by approximately 2 $3 \mathrm{yr}(\approx 23-34$ months) with significant coherence levels of 0.91 and 0.87 , respectively (Fig. 4). Real and imaginary component time series are orthogonal to each other, however these are not Hilbert transforms to each other (Horel, 1984). Note, that White and Cherry (1999) recommended to use a temporal lag between real and imaginary components in statistical climate prediction models.
The analysis of the temporal phases of the dominant complex principal components for the precipitation and temperature anomalies has shown that the dominant complex principal component temporal phase for the precipitation and temperature anomalies (Fig. 5) decreases with time for the most part of our time domain but it increases in some intermediate periods. On the one side this can be explained by the fact that the analyzed time series consist of anomalies of varied time scales. On the other hand, if the phase increases or decreases monotonically from 0 to $2 \pi$ over $\pi$, it can be inferred that a certain cyclicity exists in the anomalies time series (Venegas et al., 1998; Tourre et al., 1999). We shall demonstrate below that this may be explained when significant periodic signal components in the temporal coefficients of complex principal modes of analyzed time series exist.

\section{Cross-spectral analysis of the dominant complex prin- cipal modes of the temperature and precipitation anomaly time series and the teleconnection indices}

Earlier, Rodriguez-Puebla et al. ( 2001) carried out the crossspectral analysis of the dominant ordinal principal modes of the precipitation over the Iberian peninsula and North Atlantic Oscillation index. In this paper it was emphasized, that “... when two time series have significant peaks at particular frequencies and the peaks are coherent, the local and global information constitutes a true climate signal" (citation from: Rodriguez-Puebla et al., 2001). In this study we used the approach of the paper (Rodriguez-Puebla et al., 2001), to analyze the dominant complex principal modes of the anomaly time series and its relationship to the North-Pacific index and Arctic Oscillation index.

The dominant complex principal modes of temperature and precipitation anomalies reveal two significant spectral peaks with the period of $\approx 6-8 \mathrm{yr}(72-96 \mathrm{mo})$ and the quasibiennial oscillation with the period of 2-3 yr $(\approx 23-34 \mathrm{mo})$ (Figs. 6a, 7a, 8a). The coherence between the dominant complex principal modes of temperatures and precipitation anomalies and the Arctic and North Pacific Oscillations suggest, in general, that the presence of these oscillations at 6 $8 \mathrm{yr}$ and $2-3 \mathrm{yr}$ must be signals of variations because they are coherent at about 0.21 squared correlation. The critical value for coherency estimates is 0.16 at $95 \%$ significance level (Brillinger, 1981) (Figs. 6b, 7b, 8b). It is remarkable, that, interconnections are more stable for the dominant complex principal mode of precipitation anomalies, than temperature anomalies (the variant "complex principal mode of precipitation anomalies and arctic oscillation" is not shown). 


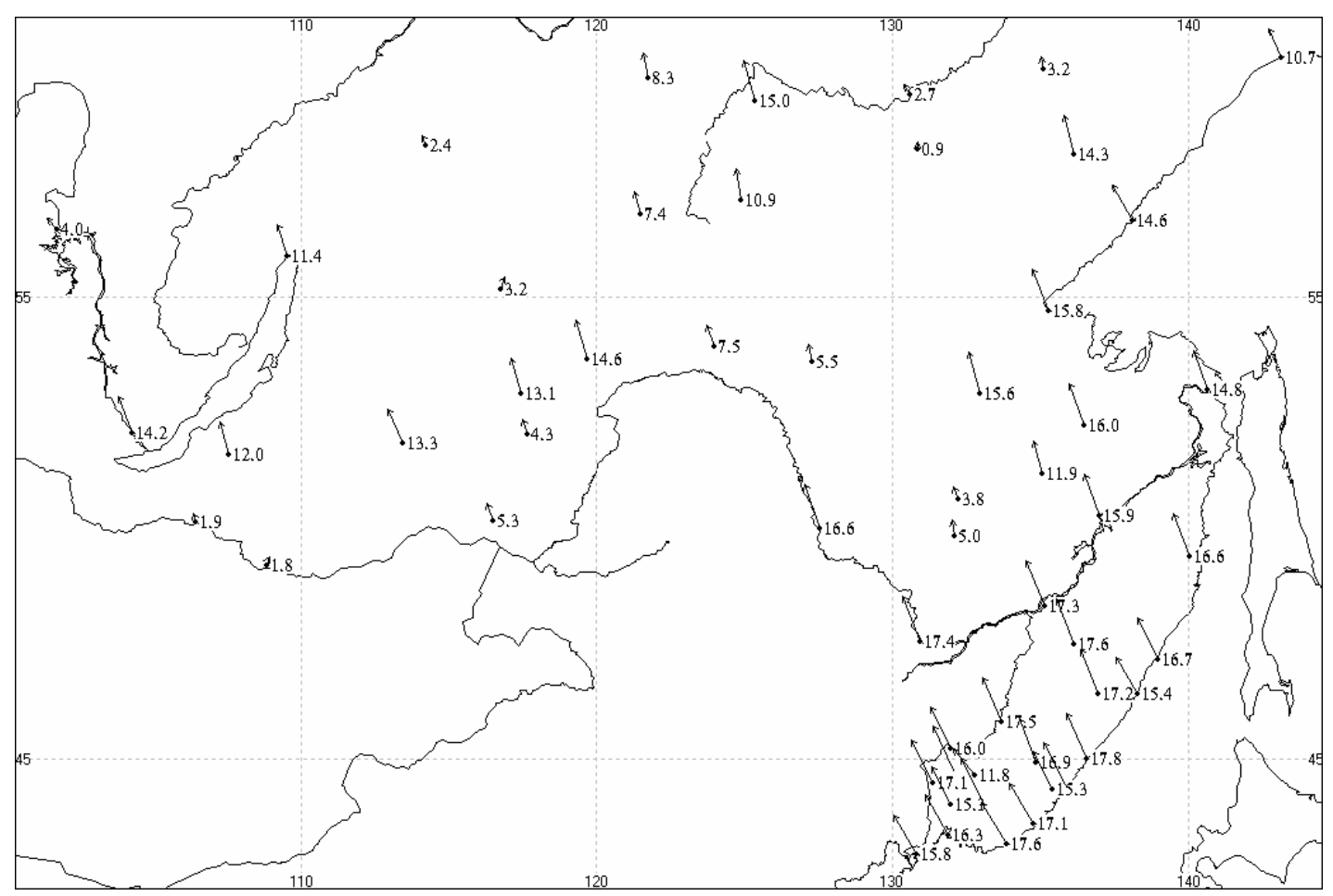

Fig. 2a. First complex principal pattern (55\% of total variance) of the Mean Monthly Temperature anomalies.

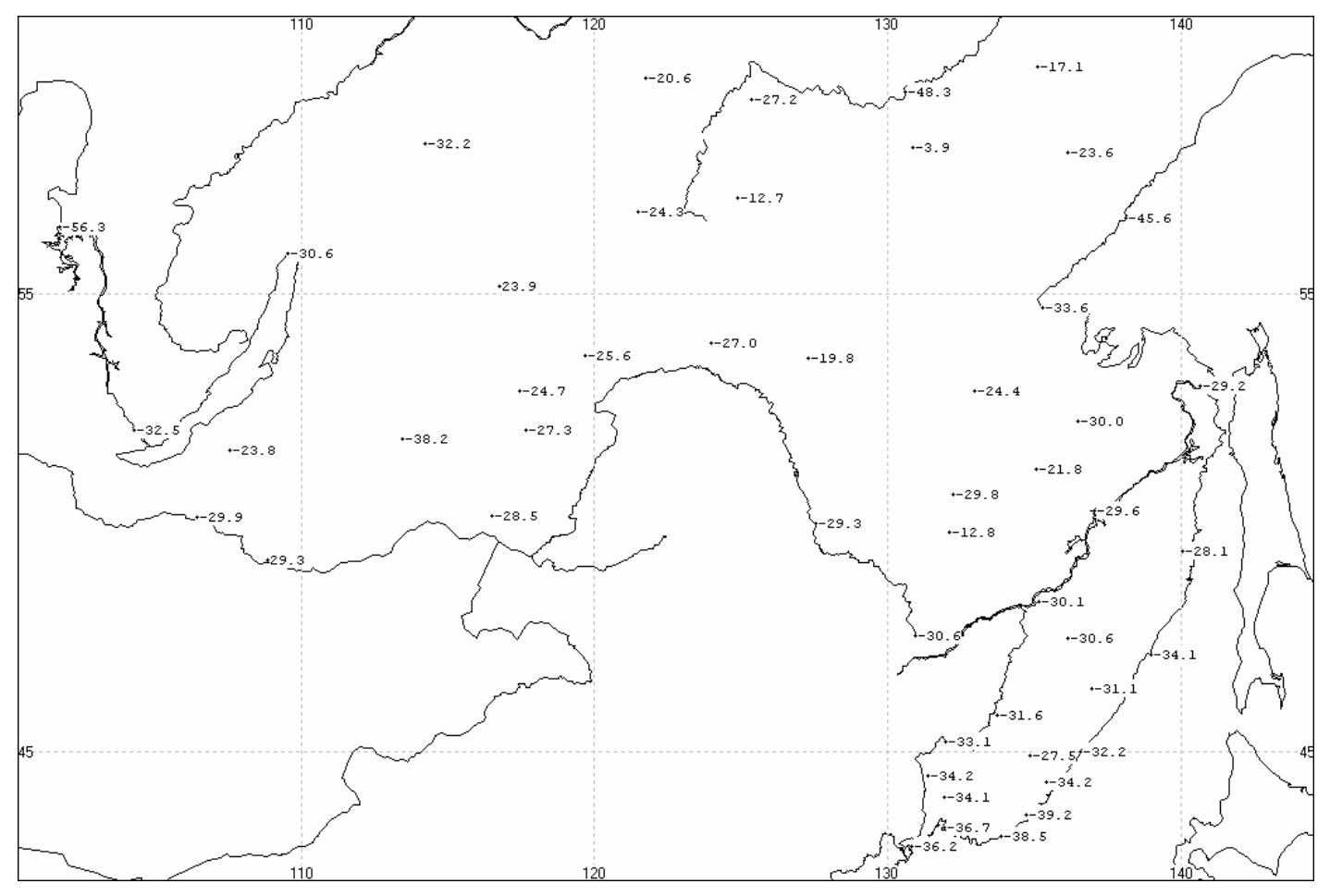

Fig. 2b. Spatial phase (in degrees) of the complex principal component of the Mean Monthly Temperature anomalies. 


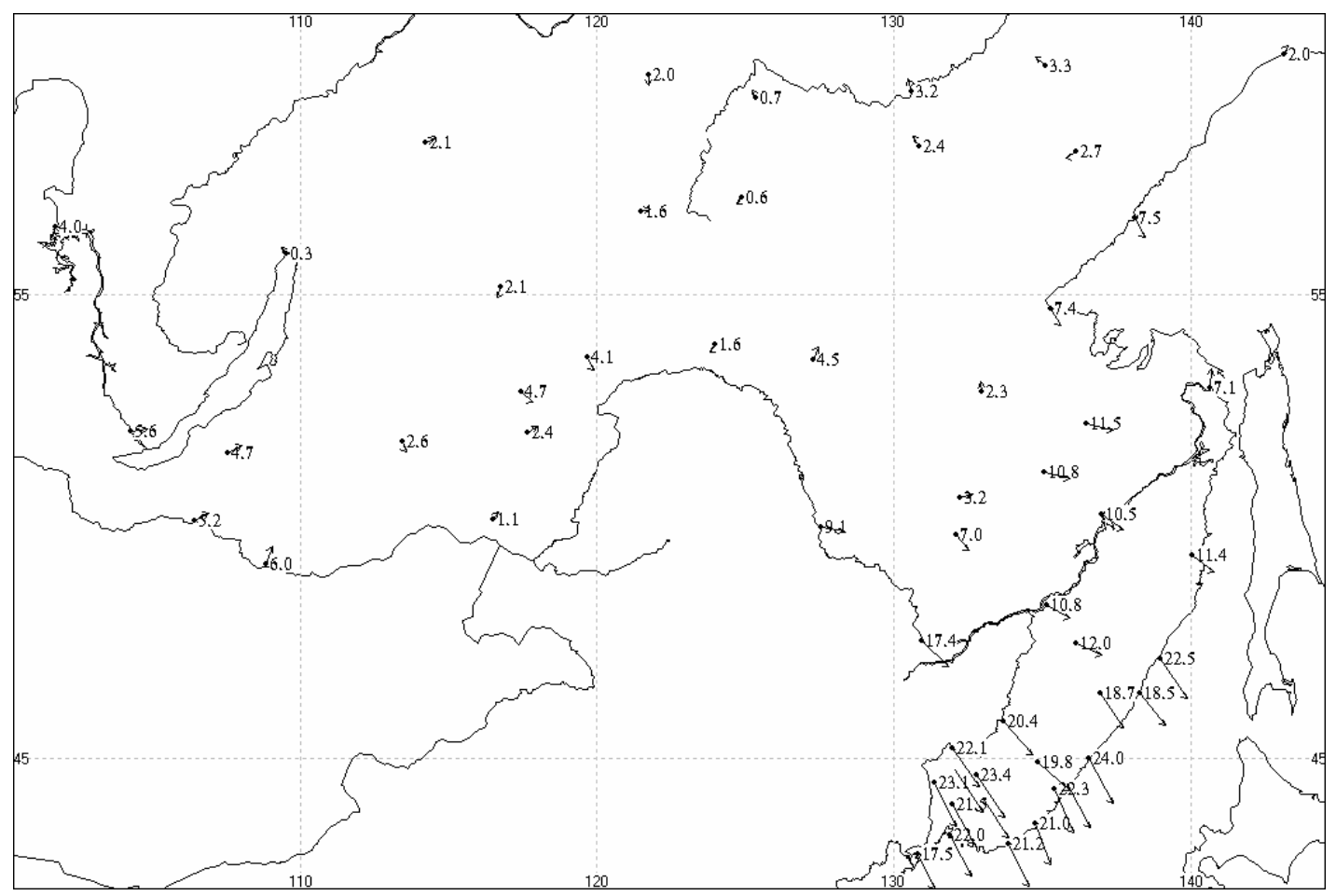

Fig. 3a. First complex principal pattern (22\% of total variance) of the Monthly Precipitation anomalies.

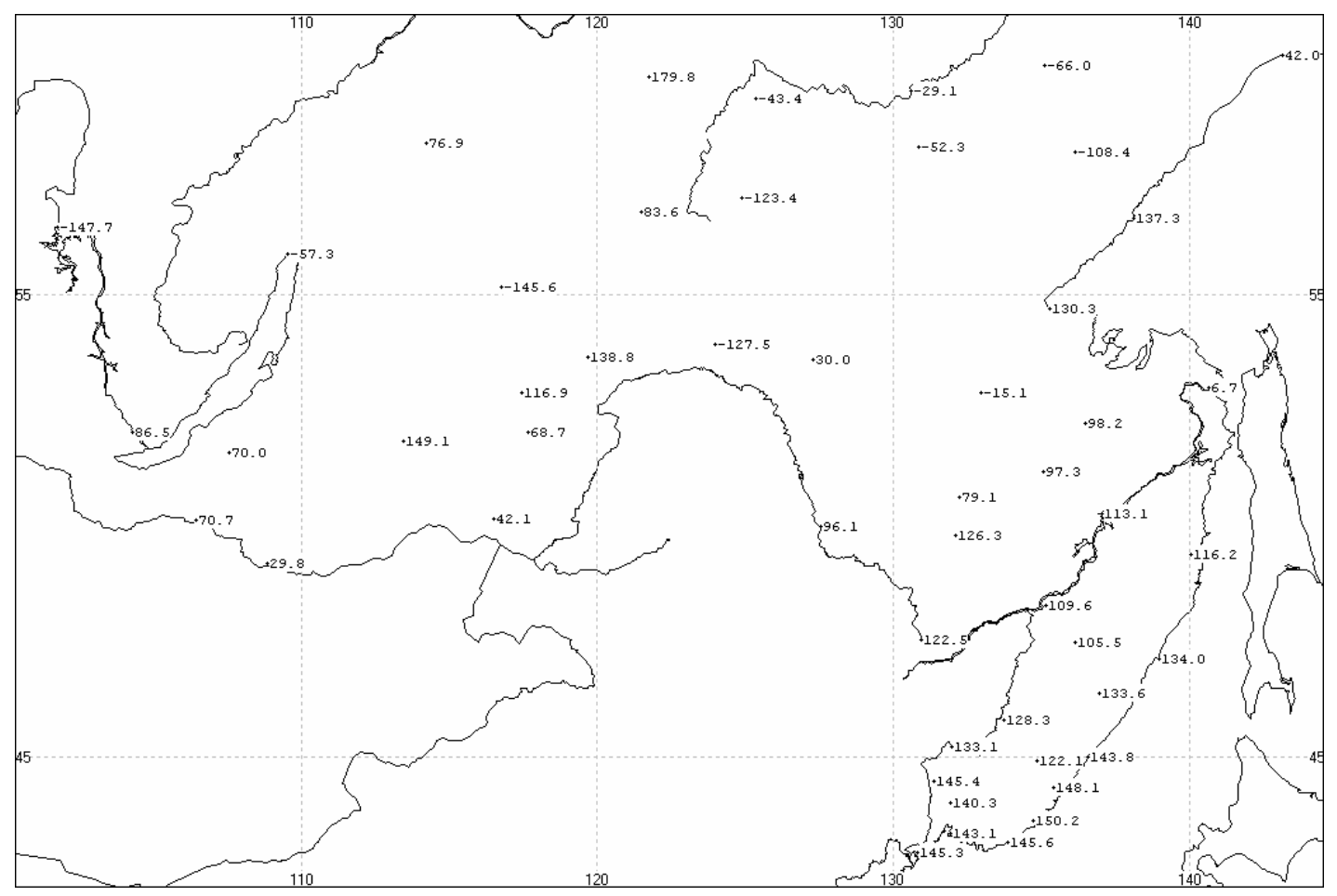

Fig. 3b. Spatial phase (in degrees) of the complex principal component of the Monthly Precipitation anomalies. 


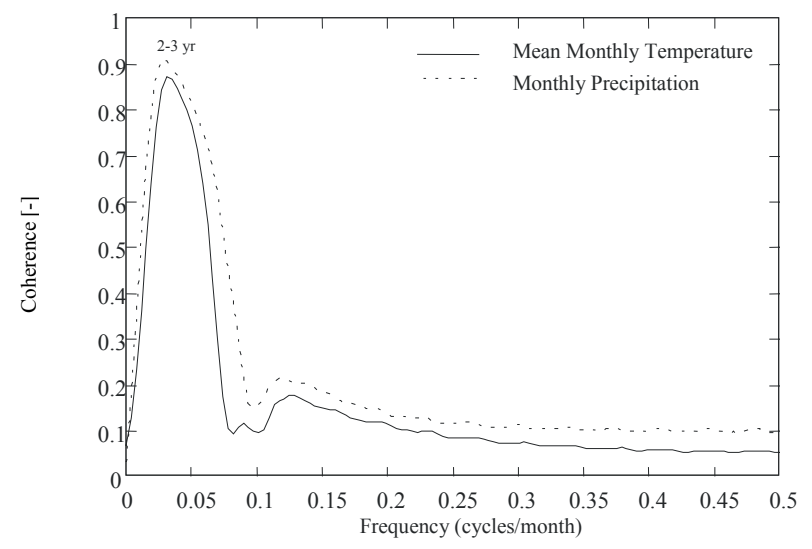

Fig. 4. Coherence between the real and imaginary parts of the temporal coefficients of the dominant principal components for the Mean Monthly Temperatures and Monthly Precipitation time series.

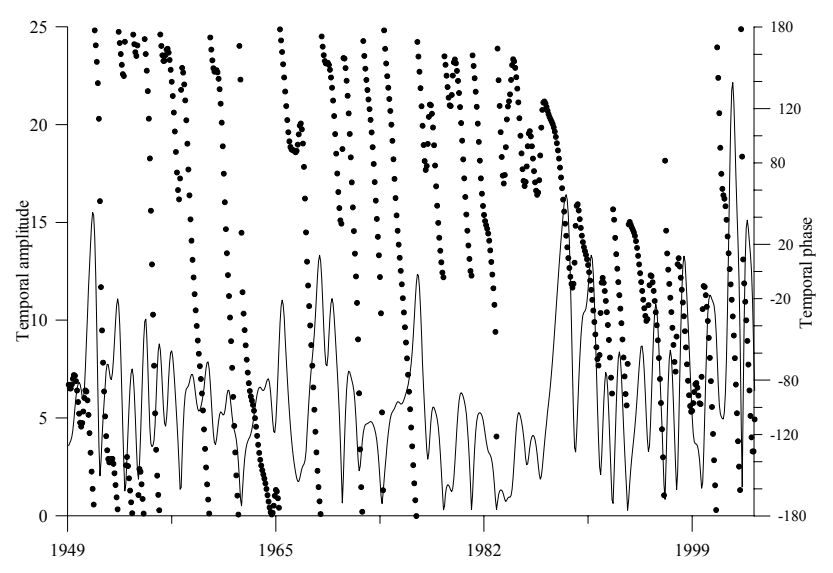

Fig. 5a. The normalized temporal coefficient (amplitude in solid line and phase in solid circles) of the CEOF pattern of the Mean Monthly Temperature anomalies.

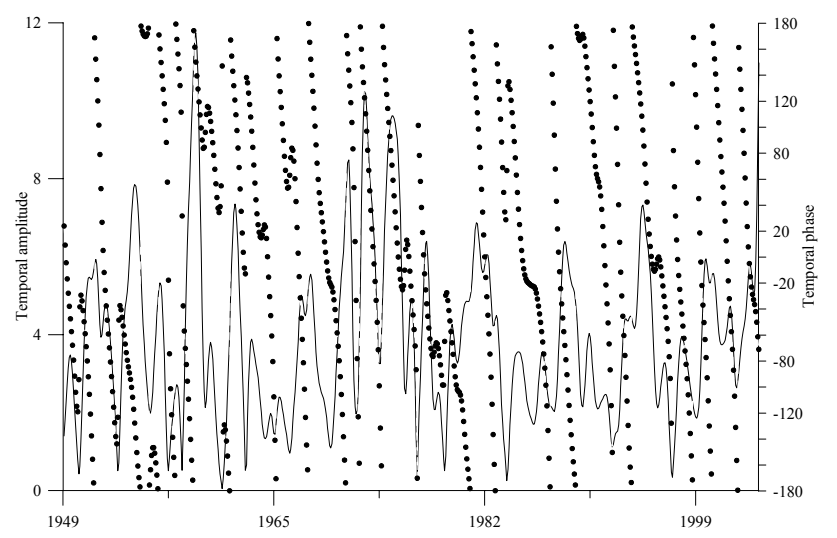

Fig. 5b. The normalized temporal coefficient (amplitude in solid line and phase in solid circles) of the CEOF pattern of the Monthly Precipitation anomalies.

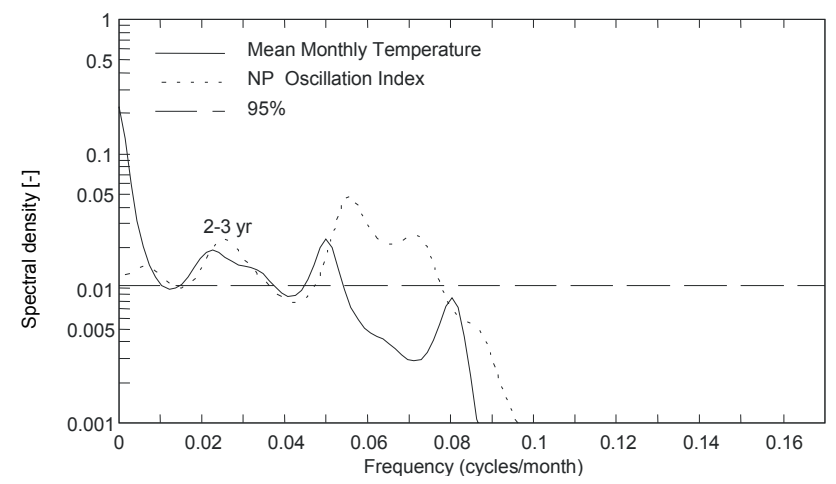

Fig. 6a. Spectra of the dominant complex principal mode of Mean Monthly Temperatures and the NP Oscillation Index.

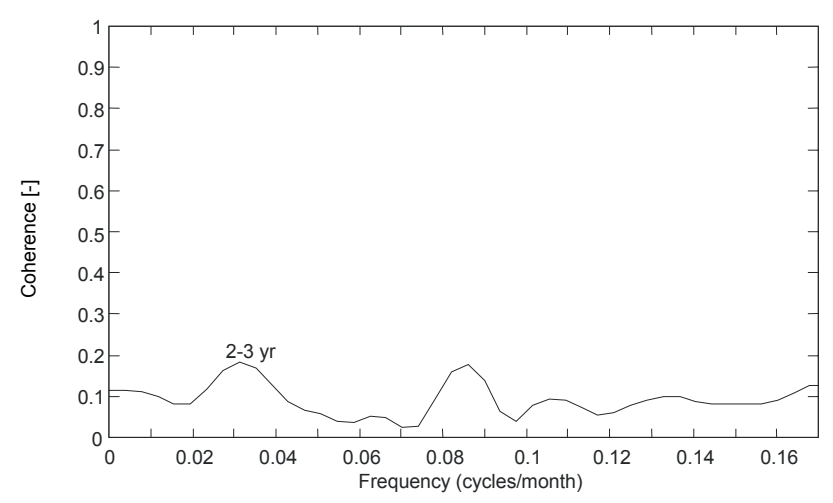

Fig. 6b. Coherence between the dominant complex principal mode of Mean Monthly Temperatures and the NP Oscillation Index.

\section{Discussion}

The results in the present study possibly suggest that the Far Eastern mean monthly temperature and monthly precipitation anomaly time series can be associated with the quasibiennial oscillation and are coherent with "El Nino-Southern Oscillation". The Southern Oscillation is the strongest climatic signal in the tropics. El Nino and La Nina are opposite phases of the "El Nino-Southern Oscillation" cycle (Troup, 1965; Philander, 1990).

Earlier, analogous results were found in surface temperature over the United States (Rasmusson et al., 1981), in annual precipitation over the Far East (Eremin, 1982), for African rainfall time series (Ropelewski and Halpert, 1987), and for Indian rainfall time series (Mooley and Parthasarathy, 1984). Shen and Lau (1995) found a quasi-biennial oscillation mode in the East Asian summer monsoon rainfall. $\mathrm{Lu}$ (2003) found the biennial oscillation signal in monthly station pressure, temperature and precipitation data in Taiwan. A midlatitude quasi-biennial oscillation was clearly identified by an in surface level pressure field over the northern hemisphere (Trenberth, 1975; Trenberth and Shin, 


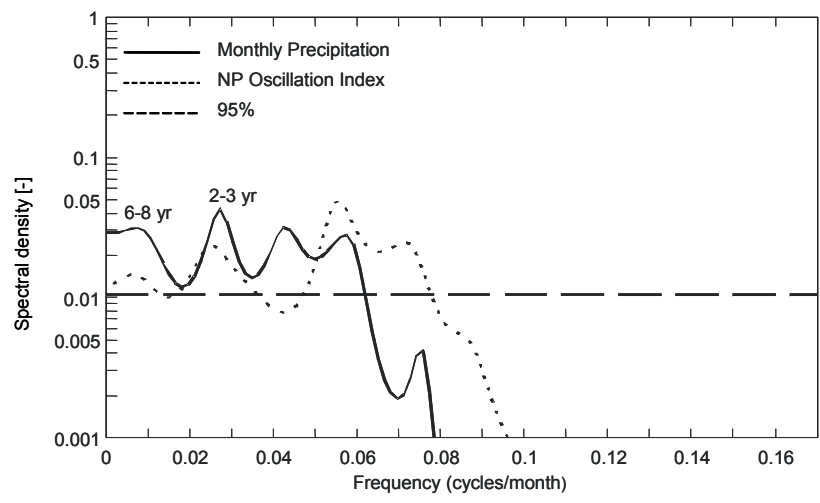

Fig. 7a. Spectra of the dominant complex principal mode of the Monthly Precipitation and the NP Oscillation Index.

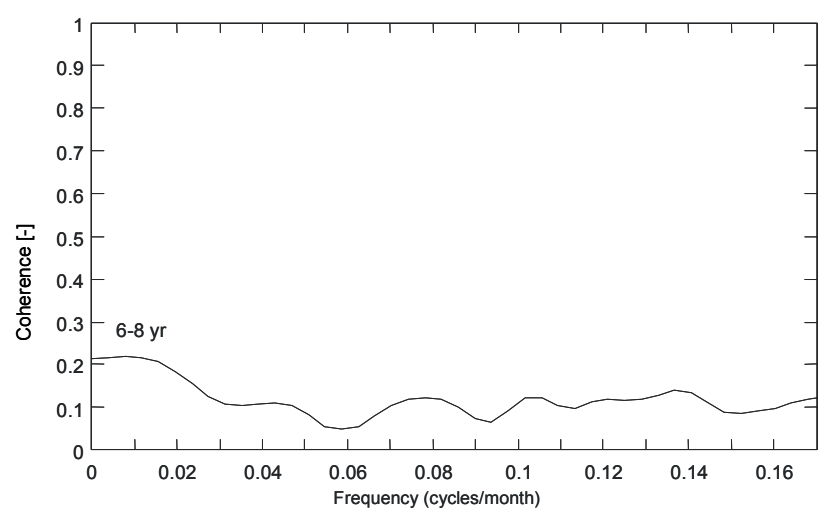

Fig. 7b. Coherence between the dominant complex principal mode of the Monthly Precipitation and the NP Oscillation Index.

1984). It was found that the quasi-biennial oscillation of sea level pressure corresponds to the fluctuations of the midlatitude wavenumber-3 planetary wave. Gong and Ho (2003) showed that Arctic Oscillation statistically significant influences upon East Asian Monsoon by way of north-south movement of the middle latitude zonal jet over East Asia.

The decadal oscillation $(\approx 8 \mathrm{yr})$ is less revealed than the quasi-biennial oscillation. Nevertheless, the existence of this oscillation is also confirmed by many investigators. For European region, e.g., Rodriguez-Puebla et al. (2001) registered the oscillation with the period of 8-yr between the North Atlantic Oscillation Index and winter precipitation over Iberian Peninsula.

For our geographical domain, Hanawa (1995) found that the Sverdrup transport and Far East Zonal Index fluctuate with the 6-8yr. periodicity over the Northwest Pacific. Tourre et al. (1999) emphasized 6-8 yr. periodicity in surface level pressure and sea surface temperature anomalies over North Pacific. Ponomarev et al. (1999) also estimated the oscillation period of sea surface temperature anomalies over North Pacific as 6-8 yr. Wang et al. (2004) examined vari-

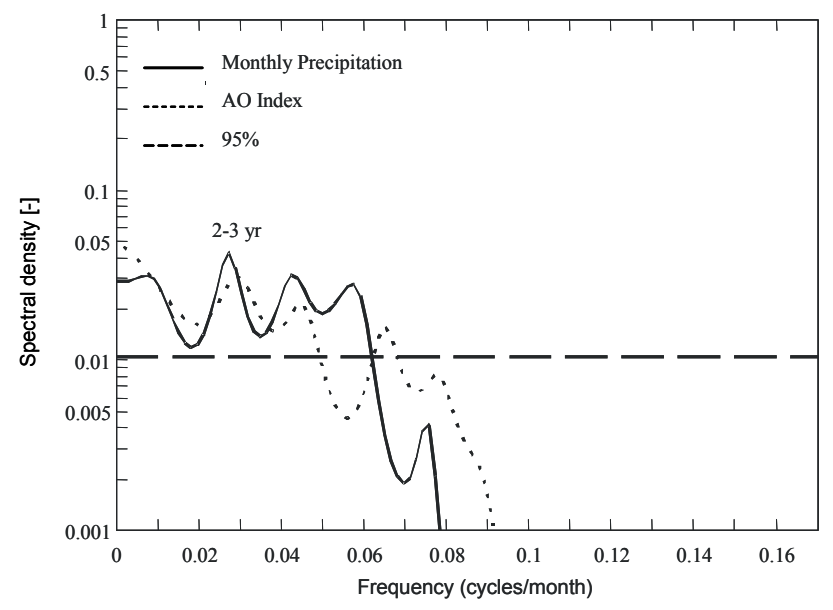

Fig. 8a. Spectra of the dominant complex principal mode of the Monthly Precipitation and the AO Index.

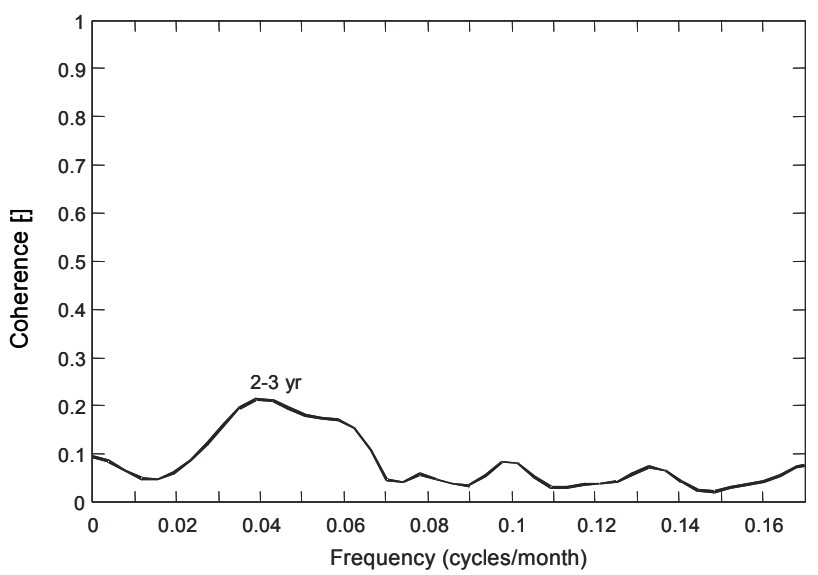

Fig. 8b. Coherence between the dominant complex principal mode of the Monthly Precipitation and the AO Index.

ability of temperature and precipitation over China and found that quasi-biennial oscillations are stronger in East China, than in West China.

The anomalies in atmospheric pressure, temperature and rainfall have similar statistically significant periodicity on the different interannual timescales in different East Asian regions. The present study does not pursue the purpose to analyze the physical nature of these interrelations. Different assumptions were suggested by many investigators. For example, Nakamura (2002) accentuated the main role of the storm activity for the East Asian monsoon intensity. We shall note only, that it is necessary to search for possible explanations, apparently, in the nature of climatic fluctuations (von Storch and Zweirs, 1999), in the so-called mechanism of long time memory in climatic systems (the ocean, the ice caps, and some land processes including the biota). As shown by Hasselmann (1976), Majda et al. (2001) and many others, research of the mechanism of long time memory is the further basis for climate modeling and, subsequently, forecasting. 


\section{Conclusions}

This paper examines the spatial and temporal variations of the mean monthly temperature and monthly precipitation totals anomalies over Russian Eastern Siberia and the Russian Far East for the period 1949-2003 and investigates their linear relationships with global climate variability, as defined by teleconnection indices such as AO and NP. From our analysis we draw the following conclusions.

1. The interannual variability in the detrended temperature and precipitation anomaly series can be represented by the first dominant complex principal modes.

2. These dominant modes oscillate with periods of about $2-3 \mathrm{yr}$ and $6-8 \mathrm{yr}$ that are accompanied by statistically significant changes in such teleconnection indices, as the Arctic and North Pacific Oscillations. Whether these modes are likely to be physically important in the earth's atmosphere is an open question, however.

Thus, the further studies of climate of Eastern Siberia and the Far East must be closely joined with studies of the West Pacific monsoon, El Nino-Southern Oscillation, surface air temperature and precipitation variations in the western $\mathrm{Pa}-$ cific and surrounding oceans, the tropospheric/stratospheric biennial oscillation, and the South Asian Monsoon.

Acknowledgements. The authors are pleased to acknowledge the support of Netherlands Organization for Scientific Research Grant 047.014.011 "Statistical Properties of Flood Runoff of North Eurasia Rivers under Conditions of Climate Change" and Russian Foundation of Basic Research 01-05-65128.

Edited by: A. Bardossy

\section{References}

Ambaum, M. H. P., Hoskins, B. J., and Stephenson, D. B.: Arctic Oscillation or North Atlantic Oscillation?, J. Climate, 14, 34953507, 2001.

Barnett, T. P.: Interaction of the Monsoon and Pacific trade wind system at interannual time scales, Part I, The equatorial zone, Mon. Weather Rev., 111, 756-773, 1983.

Barnston, A. G. and Livezey, R.E.: Classification, seasonality and persistence of low frequency atmospheric circulation patterns, Mon. Weather Rev., 115, 1083-1126, 1987.

Bell, G. D. and Halpert, M. S.: NOAA Atlas N0 12. Interseasonal and interannual variability: 1986 to 1993, Climate Analysis Center, US, NOAA, 256 pp., 1995.

Biondi, F., Gershunov, A., and Cayan, D. R.: North Pacific decadal climate variability since 1661, J. Climate, 14, 5-10, 2001.

Bloomfield, P.: Fourier analysis of time series: an introduction, John Wiley \& Sons Inc., New York, 288 pp., 2000.

Bloomfield, P. and Davis, J. M.: Orthogonal rotation of complex principal components, Int. J. Climatol., 14, 759-775, 1994.

Brillinger, D. R.: Time series: data analysis and theory, HoldenDay, San Francisco, 500 pp., 1981.
Davis, J. M., Estis, F. L., Bloomfield, P., and Monahan, J. F.: Complex principal component analysis of sea-level pressure over the eastern USA, Int. J. Climatol., 11, 27-54, 1991.

Domroes, M., Kaviani, M., and Schaefer, D.: An analysis of regional and intra-annual precipitation variability over Iran using multivariate statistical methods, Theor. Appl. Climatol., 61, 3-4, 151-159, 1998.

Eremin, P. G.: Quasi-biennial fluctuations in annual precipitation totals over the Far East, Works of FERHRI, St. Petersburg, Hydrometeorological Press, 101, 26-32, 1982 (in Russian).

Cavazos, T.: Using self-organizing maps to investigate extreme climate events: an application to wintertime precipitation in the Balkans, J. Climate, 13, 1718-1732, 2000.

Genthon, C., Krinner, G., and Sacchettini, M.: Interannual Antarctic tropospheric circulation and precipitation variability, Clim. Dynam., 21, 3-4, 289-307, 2003.

Gershunov, A., and Barnett, T.P.: Interdecadal modulation of ENSO teleconnections, B. Am. Meteorol. Soc., 79, 2715-2725, 1998.

Ghil, M. and Yiou, P.: Spectral methods: what they can and cannot do for climatic time series, in: Decadal climate variability: dynamics and predictability, edited by: Anderson, D. and Willebrand, J., Elsevier, Amsterdam, 445-482, 1996.

Gong, D.-Y. and Ho, C.-H.: Arctic Oscillation signals in the East Asian summer monsoon, J. Geophys. Res., 108(D2), 4066, doi:10.1029/2002JD002193, 2003.

Gonzalez-Rouco, J. F., Jimenez, J. L., Quesada, V., and Valero, F.: Quality Control and Homogeneity of Precipitation Data in the Southwest of Europe, J. Climate, 14, 964-978, 2001.

Hanawa, K.: Southward penetration of the Oyashio water system and the wintertime condition of midlatitude westerlies over the North Pacific, B. Hokkaido Natl. Fish. Res. Inst., 59, 103-115, 1995.

Hasselmann, K.: Stochastic climate models, Part I, Tellus, 28, 473485, 1976.

Herrmann, O.: Transversalfilter zur Hilbert-transformation, Arch. Elektr. Ubertragung, 23, 581-587, 1969.

Horel, J. D.: Complex principal component analysis: theory and examples, J. Clim. Appl. Meteorol., 23, 1660-1673, 1984.

Hulme, M. and Jones, P. D.: A historical monthly precipitation data set for global land areas: Applications for climate monitoring and climate model evolution, Analysis methods of precipitation on a global scale, WMO/TD-No. 558, Geneva, 1993.

Jenkins, G. M. and Watts, D. G.: Spectral analysis and its applications, Holden-Day, 525 pp., 1968.

Kaiser, H. F.: The varimax criterion for analytic rotation in factor analysis, Psychometrika, 23, 187-200, 1958.

King, J. R., Ivanov, V. V., Kurashov, V., Beamish, R. J., and McFarlane, G. A.: General circulation of the atmosphere over the North Pacific and its relationship to the Aleutian Low, NPAFC Doc. No. 318, 18 pp., Dept. of Fisheries and Oceans, Sciences Branch - Pacific Region, Pacific Biological Station, Nanaimo, BC, Canada, V9R 5K6. Arctic and Antarctic Research Institute, 38 Bering Street, St. Petersburg, Russia, 199397, 1998.

Krokhin, V. V.: About some methods of statistical data processing of the monthly precipitation totals, Works of FERHRI, St. Petersburg, Hydrometeorological Press., 148, 116-127, 2000 (in Russian).

Lu, Mong-Ming: The Biennial Oscillations in Taiwan, Terr. Atmos. Ocean. Sci., 13, 4, 469-498, 2003. 
Majda, A. I., Timofeyev, I., and Van Eijden, E.: A mathematical framework for stochastic climate models, Commun. Pur. Appl. Math., LIV, 0891-0974, 2001.

Mantua, N. J., Hare, S. R., Zhang, Y., Wallace, J. M., and Francis, R. C.: A Pacific interdecadal climate oscillation with impacts on salmon production, B. Am. Meteorol. Soc., 78, 1069-1079, 1997.

Merrifield, M. A. and Guza, R. T.: Detecting propagating signals with complex empirical orthogonal functions: a cautionary note, J. Phys. Oceanogr., 20(10), 1628-1633, 1990.

Mooley, D. A. and Parthasarathy, B.: Fluctuations in All-India summer monsoon rainfall during 1871-1978, Climatic Change, 6, 287-301, 1984.

Nakamura, H., Izumi , T., and Sampe, T.: Interannual and decadal modulations recently observed in the Pacific storm track activity and East Asian winter monsoon, J. Climate, 15, 1855-1874, 2002.

Overland, I. E., Adams, J. M., and Bond, N. A.: Decadal variability of the Aleutian low and its relation to high-latitude circulation, J. Climate, 12, 1542-1548, 1999.

Percival, D. B. and Walden, A. T.: Spectral analysis for physical applications. multitaper and conventional univariate techniques, Cambridge University Press, Cambridge, United Kingdom, 583 pp., 1993.

Philander, S. G.: El Nino, La Nina, and the Southern Oscillation, Academic Press, San Diego, CA, 289 pp., 1990.

Ponomarev, V. I., Trusenkova, O. O., Trusenkov, S. T., Kaplunenko, D. D., Ustinova, E. I., and Polyakova, A. M.: The ENSO signal in the Northwestern Pacific, Impacts of the 1997/98 El Nino Event on the North Pacific Ocean and its marginal seas, PICES Sci. Rep., 10, 9-32, 1999.

Preisendorfer, R. W.: Principal Component Analysis in Meteorology and Oceanography, Elsevier, New York, 425 pp., 1988

Press, W. H., Flannery, B. P., Teukolsky, S. A., and Vetterling, W. T.: Numerical recipes in FORTRAN 77 : the art of scientific computing, Second Edition, Cambridge University Press, Cambridge, UK, 933 pp., 1992.

Rabiner, L. R. and Gold, B,: Theory and application of digital signal processing, Prentice-Hall, Englewood Cliffs, New Jersey, 762 pp., 1975.

Rasmusson, E. M., Arkin, P. A., Chen, W.-Y., and Jalickee, J. B.: Biennial variations in surface temperature over the United States as revealed by singular decomposition, Mon. Weather Rev., 109, 587-598, 1981

Rodriguez-Puebla, C., Encinas, A. H., and Saenz, J.: Winter precipitation over the Iberian peninsula and its relationship to circulation indices, Hydrol. Earth Syst. Sci., 5, 233-244, 2001,

http://www.hydrol-earth-syst-sci.net/5/233/2001/.

Ropelewski, C. F. and Halpert, M. S.: Global and regional scale precipitation patterns associated with El Nino/Southern Oscillation, Mon. Weather Rev., 115, 1606-1626, 1987.

Salinger, M. J.: New Zealand climate: I. Precipitation patterns, Mon. Weather Rev., 108, 1892-1904, 1980a.

Salinger, M. J.: New Zealand climate: II. Temperature patterns, Mon. Weather Rev., 108, 1905-1912, 1980b.

Schafer, J. L.: Analysis of incomplete multivariate data, Chapman \& Hall, London, 448 pp., 1997.

Schultz, M. and Stattegger K.: Spectrum: Spectral analysis of unevenly spaced paleoclimatic time series, Comput. Geosci., 23, 9,
929-945, 1997.

Shen, A. and Lau, K.: Biennial oscillation associated with the EastAsian summer monsoon and tropical sea-surface temperature, J. Meteorol. Soc. Japan, 73, 105-124, 1995.

Svinukhof, G. V.: Synoptic-statistical methods of the longterm weather forecasts in Far East, Gidrometeoizdat Press, St.Peterburg, 168 pp., 1977 (in Russian).

Thompson, D. W. J. and Wallace, J. M.: The Arctic Oscillation signature in the winter time geopotential height and temperature fields, Geophy. Res. Lett., 25, 1297-1300, 1998.

Thompson, D. W. J. and Wallace, J. M.: Annular modes in the extratropical circulation, Part I: Month-to-month variability, J. Climate, 13, 1000-1016, 2000

Thompson, D. W. J., Wallace, J. M., and Hegerl, G. C.: Annular modes in the extratropical circulation, Part II: Trends, J. Climate, 13, 1018-1036, 2000

Tourre, Y. M., Kushnir Y., and White, W. B.: Evolution of interdecadal variability in sea level pressure, sea surface temperature, and upper ocean temperature over the Pacific Ocean, J. Phys. Oceanogr., 29, 1528-1541, 1999.

Trenberth, K. E.: A quasi-biennial standing wave in the Southern Hemisphere and interrelations with sea surface temperature, Q. J. Roy. Meteor. Soc., 101, 55-74, 1975.

Trenberth, K. E. and Shin, W. K.: Quasi-biennial fluctuations in sea level pressures over the northern hemisphere, Mon. Weather Rev., 112, 761-777, 1984.

Troup, A. J.: The Southern Oscillation, Q. J. Roy. Meteor. Soc., 91, 490-506, 1965.

Varlamov, S. M., Kim, Y.-S., and Han, Y.-H.: Recent variations of temperature in Eastern Siberia and the Russian Far East, Meteorology and Hydrology, 1, 19-28, 1998.

Venegas, S. A., Musak, L. A., and Straub, D. N.: An interdecadal climate cycle in the South Atlantic and its links to other ocean basins, J. Geophys. Res., 103(C11), 24 723-24 736, 1998.

Von Storch, H. and Zwiers, F. W.: Statistical Analysis in Climate Research, Cambridge University Press, 484 pp., 1999.

Wang, S., Jinhong, Z., and Jingning, C.: Interdecadal variability of temperature and precipitation in China since 1880, Adv. Atmos. Sci., 21, 3, 307-313, 2004.

Watson, R. T. and the Core Writing Team (Eds.).: Climate Change 2001: The Scientific basis - contribution of working group I to the IPCC third assessment report, Cambridge University Press, Cambridge, UK, 398 pp., 2001.

Welch, P. D.: The use of fast Fourier transform for the estimation of power spectra: a method based on time averaging over short modified periodograms, IEEE Trans. Audio and Electroacoustics, AU-17, 209-215, 1967.

White, W. B.: Influence of the Antarctic circumpolar wave on Australian precipitation from 1958 to 1997, J. Climate, 13, 21252141, 2000:

White, W. B. and Cherry, N. J.: Influence of the Antarctic Circumpolar Wave upon New Zealand temperature and precipitation during autumn-winter, J. Climate, 12, 960-976, 1999.

Yuan, X. and Martinson, D. G.: Antarctic sea ice extent variability and its global connectivity, J. Climate, 13, 1697-1717, 2000. 